\title{
PERIKANAN TUNA SKALA RAKYAT (SMALL SCALE) DI PRIGI, TRENGGALEK-JAWA TIMUR
}

\author{
Erfind Nurdin \\ Peneliti pada Balai Riset Perikanan Laut, Muara Baru-Jakarta \\ Teregristrasi I tanggal: 18 September 2007; Diterima setelah perbaikan tanggal: 16 Januari 2008; \\ Disetujui terbit tanggal: 12 Januari 2009
}

\begin{abstract}
ABSTRAK
Tulisan ini membahas tentang perikanan tuna skala kecil. Penelitian telah dilakukan di salah satu pusat pendaratan tuna di selatan Jawa, yaitu Pelabuhan Perikanan Nusantara Prigi, TrenggalekJawa Timur. Alat tangkap utama yang digunakan oleh nelayan Prigi untuk menangkap ikan tunacakalang adalah, jaring insang hanyut (drift gill net), pancing ulur (hand line), dan tonda (troll lines). Kegiatan penangkapan ikan dilakukan di perairan selatan Jawa dengan menggunakan rumpon. Musim ikan terjadi pada bulan Agustus-Desember dengan puncak musim pada bulan Oktober. Sebaran panjang cagak (fork length) dominan untuk beberapa jenis sebagai berikut yellowfin berkisar $46-50 \mathrm{~cm}(40,0 \%)$ dan bigeye berkisar $46-50 \mathrm{~cm}$ (76,0\%). Hubungan panjang bobot menunjukkan pertambahan panjang lebih cepat dari bobot (Alometrik negatif).
\end{abstract}

KATAKUNCI: perikanan tuna, skala rakyat, Prigi

\section{PENDAHULUAN}

Pemanfaatan sumber daya ikan tuna di perairan Samudera Hindia dari tahun ke tahun menunjukkan kecenderungan terus meningkat. Hal ini terindikasi dengan semakin bertambahnya ijin usaha penangkapan dan jumlah armada yang beroperasi di wilayah perairan tersebut. Agar pemanfaatan sumber daya ikan tetap terjamin dan kelestarian sumber daya ikan tetap terjaga, maka perlu diupayakan manajemen yang tepat. Untuk maksud tersebut, maka informasi yang akurat diperlukan untuk menganalisis status pemanfaatan sumber daya ikan.

Pemanfaatan ikan tuna di Samudera Hindia dilakukan dengan dua cara, yaitu ikan tuna industri dan perikanan skala kecil (small scale). Pemanfaatan ikan tuna industri terutama dilakukan dengan menggunakan alat tangkap tuna long line, dan ditujukan menangkap ikan-ikan tuna besar pada kedalaman lebih dari 100-300 m dan di bawah thermoklin. Sedangkan perikanan tuna skala kecil (small scale) di Samudera Hindia dilakukan dengan menggunakan alat tangkap gill net, payang, pancing ulur, tonda, dan pukat cincin (Mertha et al., 2006).

Pemanfaatan sumber daya tuna di perairan Samudera Hindia, terutama di selatan Jawa dan barat Sumatera dari tahun ke tahun cenderung terus meningkat. Hal ini diindikasikan dengan semakin bertambahnya ijin usaha penangkapan dan jumlah armada yang beroperasi di wilayah perairan tersebut.

Salah satu pusat pendaratan tuna di selatan Jawa adalah Pelabuhan Perikanan Nusantara Prigi,
Trenggalek-Jawa Timur. Tulisan ini menggunakan data yang diperoleh melalui kegiatan penelitian di sentra pendaratan ikan (tanggal 3-7 September 2008) di Pelabuhan Perikanan Nusantara Prigi, TrenggalekJawa Timur. Data sekunder berasal dari data statistik dinas perikanan setempat dan data primer hasil interview dengan nelayan dan pengukuran langsung di lapangan.

\section{Alat Tangkap dan Produksi}

Alat tangkap utama yang digunakan oleh nelayan Prigi untuk menangkap ikan tuna-cakalang di perairan Samudera Hindia adalah jaring insang hanyut (drift gill net), pancing ulur (hand line), dan tonda (troll lines). Kegiatan penangkapan dilakukan di perairan selatan Jawa dengan menggunakan rumpon.

Alat tangkap jaring insang dan pancing ulur di Pelabuhan Perikanan Nusantara Prigi, Trenggalek pada tahun 2000-2003 tidak mengalami penambahan jumlah unit penangkapan yang tinggi (Gambar 1). Pada tahun 2004, kedua alat tangkap ini mengalami perkembangan yang cukup pesat, yaitu $70 \%$ untuk alat tangkap jaring insang dan pancing ulur mencapai $400 \%$. Alat tangkap pancing tonda mulai digunakan pada tahun 2004 oleh nelayan Prigi. Hal ini kemungkinan disebabkan oleh meningkatnya penggunaan rumpon yang dilakukan nelayan sebagai alat bantu pengumpul ikan dalam operasional penangkapan.

Produksi ikan tuna dan cakalang yang didaratkan di Pelabuhan Perikanan Nusantara Prigi dari tahun 2000-2007 mengalami perubahan (Gambar 2). 


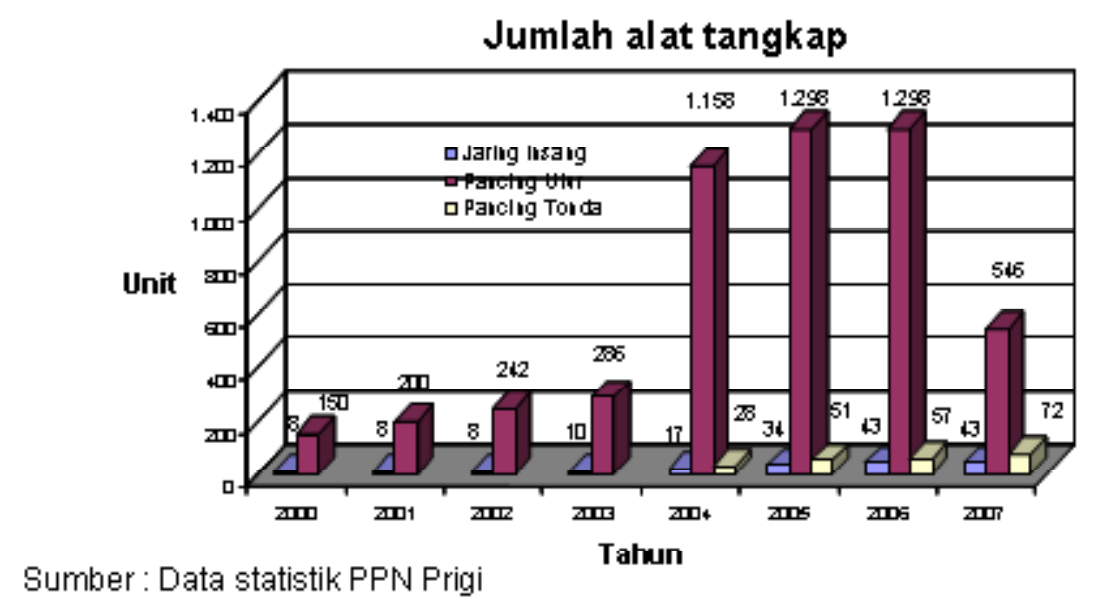

Gambar 1. Perkembangan alat tangkap tuna-cakalang di Pelabuhan Perikanan Nusantara Prigi.

\section{Produksi ikan}

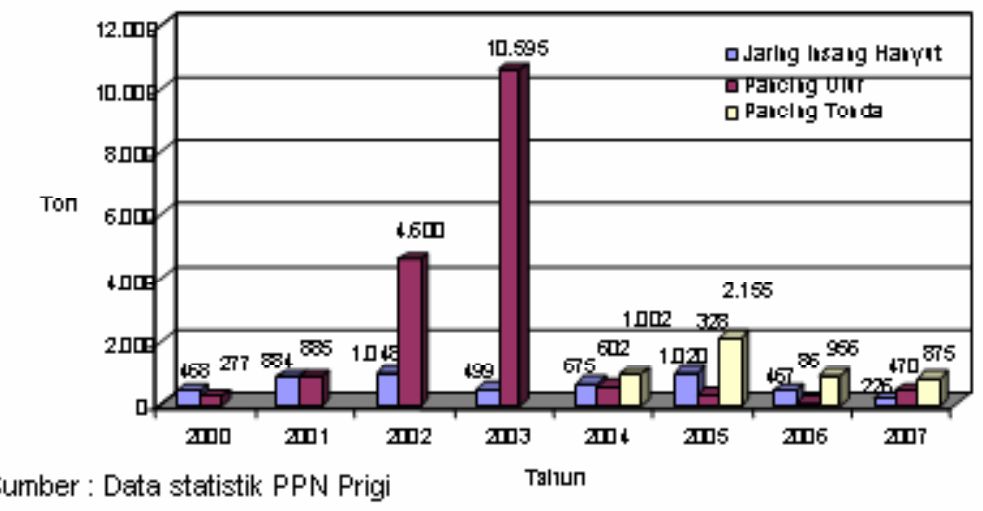

Gambar 2. Produksi alat tangkap tuna-cakalang di Pelabuhan Perikanan Nusantara Prigi.

Produksi tertinggi untuk alat tangkap jaring insang hanyut terjadi pada tahun 2005, yaitu 1.020 ton dan terendah pada tahun 2007, yaitu 226 ton. Pancing ulur mengalami produksi tertinggi pada tahun 2003 yaitu 10.595 ton dan terendah pada tahun 2006 yaitu 86 ton. Pancing tonda mengalami produksi tertinggi pada tahun 2005 yaitu 2.155 ton dan mengalami penurunan sampai 875 ton pada tahun 2007 . Penurunan jumlah produksi per tahun ini ditengarai terjadi karena meningkatnya jumlah armada yang melakukan operasional di daerah penangkapan (fishing ground) yang sama sehingga terjadi persaingan yang ketat (Gambar 2).

\section{Musim dan Catch Per Unit of Effort}

Pendaratan ikan di Pelabuhan Perikanan Nusantara Prigi terjadi pada bulan Agustus-Desember dengan puncaknya pada bulan Oktober. Pada bulan-bulan tersebut terjadi kenaikan produksi bila dibandingkan dengan bulan lainnya. Pada awal sampai pertengahan tahun (bulan Januari-Juni) terjadi penurunan tajam aktivitas penangkapan ikan (Gambar 3). Musim yang kurang menguntungkan, seperti angin kencang dan gelombang air laut yang tinggi diduga berpengaruh terhadap sistem penangkapan.

Berdasarkan pada data tahun 2000-2007, catch per unit of effort cenderung menurun. Nilai catch per unit of effort jaring insang hanyut mengalami kenaikan dari tahun 2000-2002, kemudian mengalami penurunan tajam sampai 2007. Untuk pancing ulur kenaikan terjadi dari tahun 2000-2003 dan terus mengalami penurunan sampai tahun 2007. Begitu pula pancing tonda mengalami kenaikan dari tahun 20042005 yang kemudian menurun sampai tahun 2007 (Gambar 4).

Penurunan nilai catch per unit of effort diduga disebabkan oleh karena produktivitas kapal yang ditunjukkan oleh nilai catch per unit of effort, jumlah kapalnya bertambah dengan asumsi jumlah stok ikan 
tetap, sehingga menurun. Penurunan stok ikan diindikasikan dengan semakin jauhnya daerah penangkapan (fishing ground) yang dilakukan oleh nelayan.

\section{Alat Penangkapan Ikan}

\section{Jaring Insang}

Jaring insang (gill net) merupakan alat tangkap dengan kontruksi utama berupa jaring (webbing). Bentuknya adalah lembaran jaring empat persegi panjang dengan ukuran mata jaring yang sama pada keseluhuhannya (Gambar 5). Pada umumnya ikan tertangkap dengan cara tersangkut di bagian insangnya. Jaring insang tergolong alat tangkap ikan yang pasif. Jaring dioperasikan pada sekitar rumpon atau daerah penangkapan yang cocok. Setelah jaring ditawur (setting), maka akan dibiarkan menghanyut (drift) selama 4-6 jam. Pengangkatan jaring (haulling) dilakukan sambil melepas hasil tangkapan yang telah tersangkut.

Jaring insang dioperasikan pada malam hari sampai menjelang subuh dengan menggunakan bantuan lampu mercury 500 watt 4 buah. Jaring dipasang (setting) sejauh kurang lebih 1 mil dari rumpon. Lampu dinyalakan pada rumpon, setelah ikan

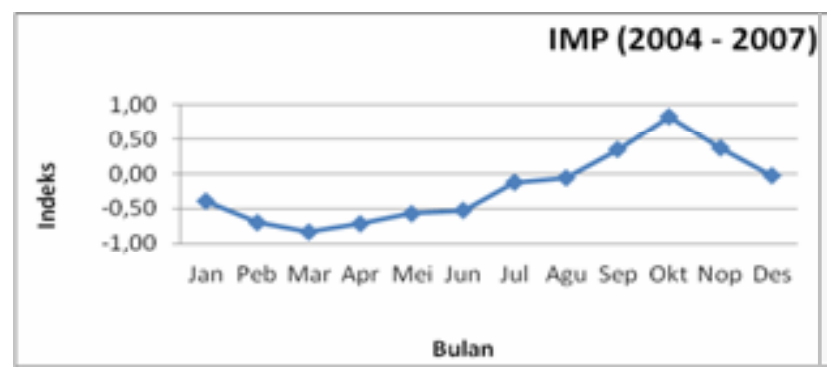

Gambar 3. Indeks musim penangkapan (data 2004-2007).

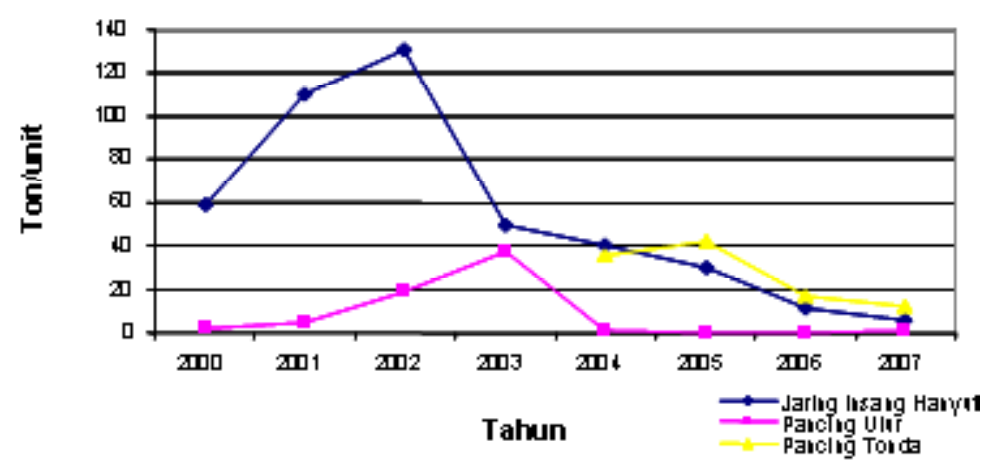

Gambar 4. Catch per unit of effort alat tangkap tuna-cakalang di PPN Prigi.

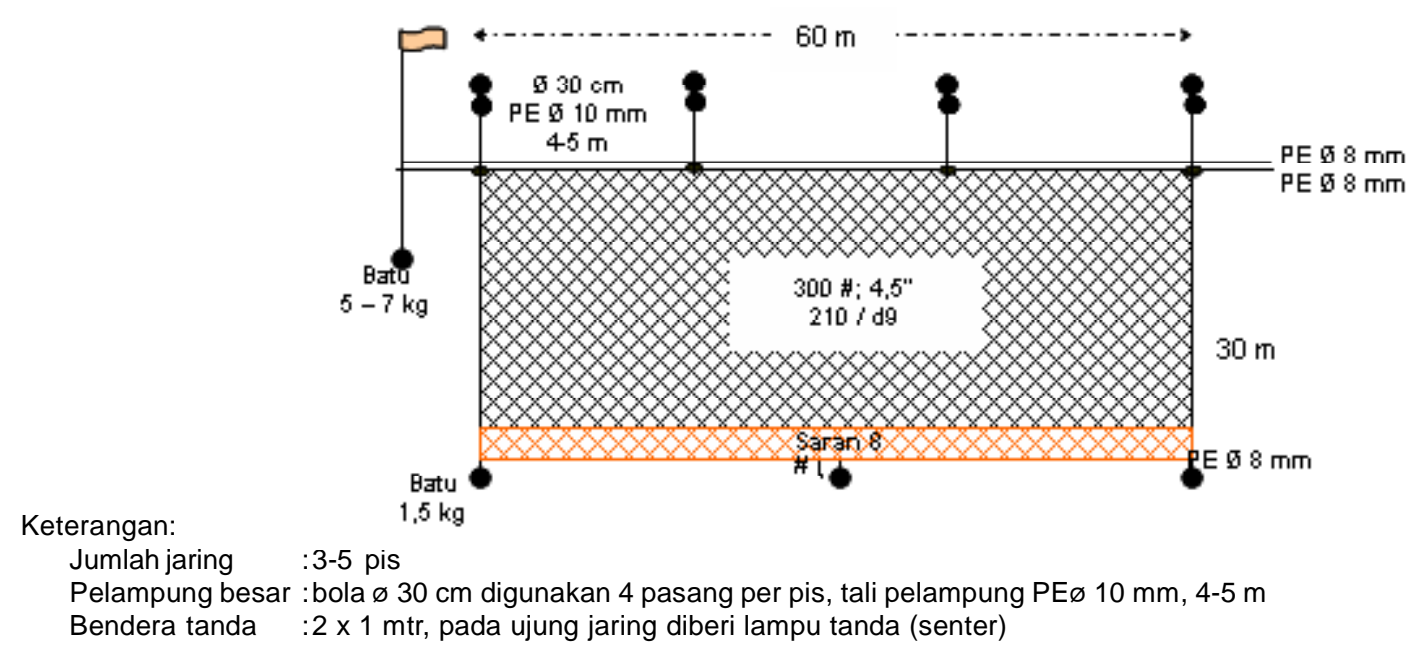

Gambar 5. Konstruksi 1 pis jaring insang (gill net) nelayan Prigi. 


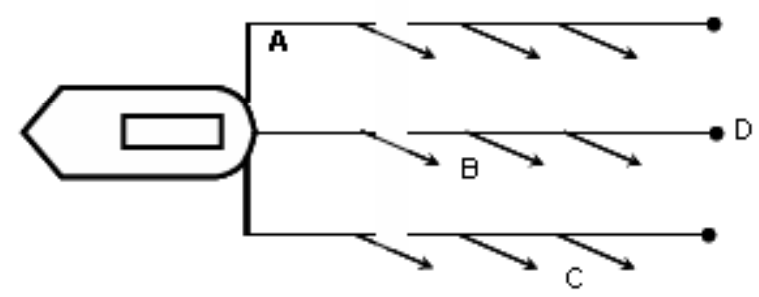

Keterangan:

A. Tali utama: 1 gulung senar no.1.000 (100-200 m)

B. Tali pancing: Senar no.200, 12-15 buah, @ panjang 0,5 m, jarak antar tali pancing $1 \mathrm{~m}$

C. Mata pancing no.9

D. Pemberat: $1 \mathrm{~kg}$

Gambar 6. Pancing tonda nelayan PPN Prigi.

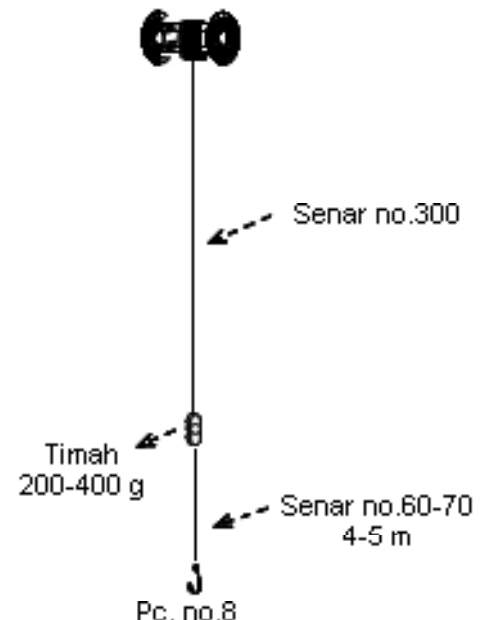

Gambar 7. Pancing tangan nelayan PPN Prigi.

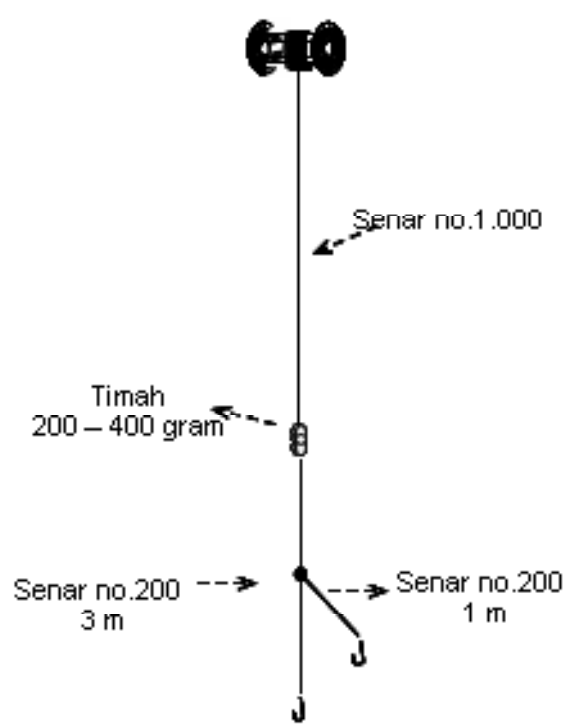

Pc. no.8 mengumpul, lampu ditarik perlahan menuju ke arah jaring. Kemudian gerombolan ikan diarahkan untuk melewati (menabrak) jaring yang telah terpasang.

\section{Pancing Tonda}

Pancing tonda (troll line) merupakan alat tangkap dengan konstruksi terdiri atas pancing, tali pancing, dan pemberat (Gambar 6). Pengoperasian tonda pada umumnya menggunakan umpan palsu. Pengoperasian pancing tonda membutuhkan perahu atau kapal bermotor. Unit pancing dioperasikan di bagian buritan kapal, sementara kapal melaju dengan kecepatan tartentu (antara 6-8 knot).

Selain alat tangkap pancing tonda, nelayan juga membawa alat tangkap jaring insang (Gambar 5) dan pancing ulur (Gambar 7). Pengoperasian tonda dilakukan pagi sampai menjelang sore hari. Untuk mengisi waktu luang nelayan memanfaatkannya dengan menggunakan pancing ulur. Pada malam hari jaring insang dipasang dengan menggunakan bantuan lampu Galaxy 500 watt 2 buah.

\section{Pancing Ulur}

Pancing ulur (hand lines) yang digunakan untuk menangkap tuna, dioperasikan pada siang hari pada umumnya di sekitar rumpon. Pancing ulur dioperasikan dengan menggunakan perahu bermotor ukuran kecil (tergantung daerah penangkapan). Konstruksi pancing ulur sangat sederhana, terdiri atas pancing (no.6-8), pemberat timah dan tali pancing dengan bahan senar monofilament (Gambar 7). Pengoperasian pancing ulur menggunakan umpan palsu atau potongan ikan kecil.

Spesifikasi kapal nelayan ikan tuna cakalang skala kecil di Prigi menggunakan bahan utama kayu dengan kisaran panjang 12,5-19,0 m, lebar 2,0-3,5 m, dan dalam 1,0-1,3 m. Ukuran palkah yang digunakan 3-4 ton, mesin ganda berukuran 24-30 pk dengan lama operasional 4-7 hari per trip (Tabel 1). 
Tabel 1. Spesifikasi kapal

\begin{tabular}{clccc}
\hline No. & \multicolumn{1}{c}{ Spek kapal } & Jaring insang & Pancing ulur & Tonda \\
\hline 1. & Nama (KM) & Mina Bahari & Putihan & Karmila \\
2. & Bahan utama & Kayu & Kayu & Kayu \\
3. & Panjang (m) & 12,7 & 13,8 & 18,6 \\
4. & Lebar (m) & 2,5 & 2 & 3,2 \\
5. & Dalam (m) & 1 & 1,3 & 1,25 \\
6. & Tonase (GT) & - & - & - \\
7. & Palkah (ton) & 4 & 3 & 3 \\
8. & Mesin (PK) & Dongfeng 24PK (2 bh) & Dongfeng 24PK (2 bh) & Yanmar 30 PK (2 bh) \\
9. Jumlah ABK (org) & $4-5$ & $4-5$ & $4-6$ \\
10. Trip (hari) & $5-7$ & $5-7$ & $4-7$ \\
\hline
\end{tabular}

Sumber: pengukuran dan wawancara langsung dengan nelayan
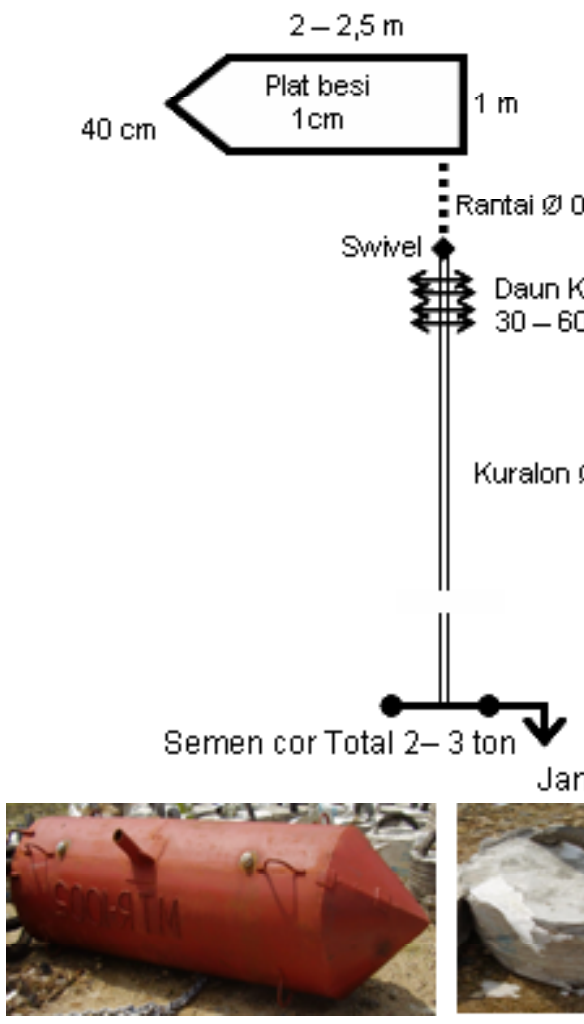

Jangkar

Gambar 8.

Konstruksi rumpon nelayan Prigi.

\section{Rumpon}

Masyarakat nelayan Prigi khususnya yang menjadikan ikan tuna-cakalang sebagai sasaran spesies utama penangkapan ikan, menggunakan bantuan rumpon sebagai alat bantu untuk mengumpulkan ikan. Bahan dasar rumpon terdiri atas ponton besi sebagai pelampung, tali temali (rantai besi dan kuralon), daun kelapa sebagai tempat ikan berkumpul, semen cor, dan jangkar sebagai pemberat (Gambar 8).

\section{Fishing Ground}

Daerah penangkapan (fishing ground) nelayan tuna cakalang skala kecil di Prigi meliputi daerah selatan
Prigi, Pacitan, sampai dengan Sadeng dan Parang Tritis (Yogyakarta) (Gambar 9)

\section{Ikan Hasil Tangkapan}

Hasil tangkapan nelayan di dominansi oleh jenis ikan tuna (yellowfin dan bigeye), cakalang, dan tongkol. Ikan tuna yang tertangkap (yellowfin dan bigeye) relatif berukuran kecil. Hasil tangkapan sampingan (by-catch) yang tertangkap berupa ikan lemadang, sunglir, dan marlin.

Pengambilan contoh biologi (panjang dan bobot) dilakukan terhadap ikan dominan hasil tangkapan yang didaratkan di Pelabuhan Perikanan Nusantara Prigi Trenggalek. Sebaran panjang cagak (fork length) 


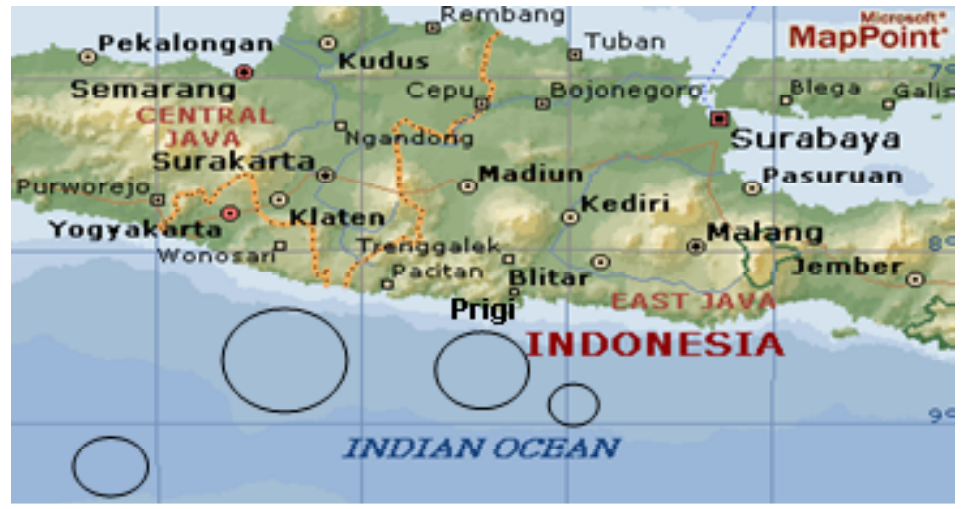

Gambar 9. Daerah penangkapan nelayan Prigi.

Kisaran FL

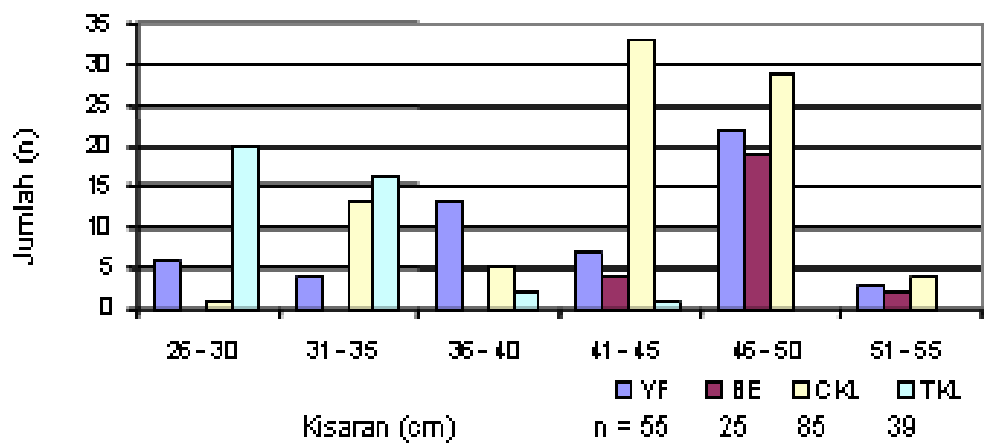

Gambar 10. Kisaran panjang cagak (fork length) hasil tangkapan nelayan Prigi.

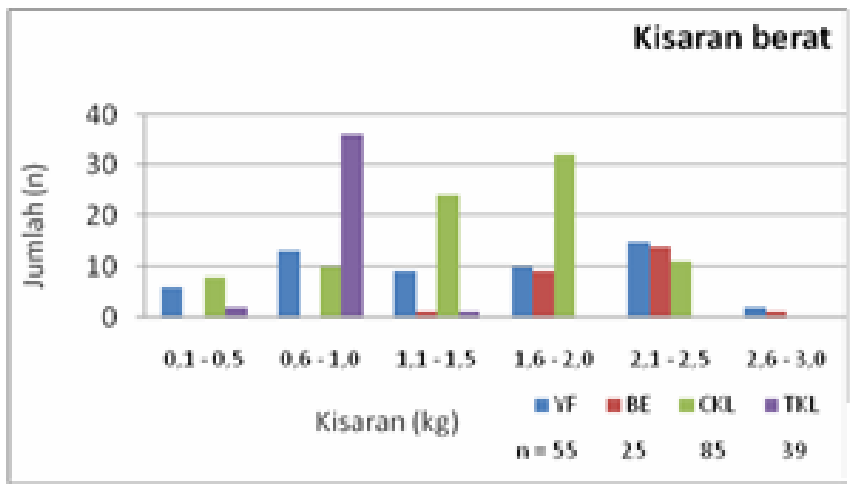

Gambar 11. Kisaran bobot $(\mathrm{kg})$ ikan hasil tangkapan nelayan Prigi.

yellowfin yang berhasil diukur 55 ekor dengan dominansi pada kisaran $46-50 \mathrm{~cm}(40,0 \%)$, bigeye (25 ekor) berkisar $46-50 \mathrm{~cm}(76,0 \%)$, dan cakalang (85 ekor) berkisar $41-46 \mathrm{~cm}(38,8 \%)$, dan tongkol (39 ekor) berkisar $26-30 \mathrm{~cm}$ (51,3\%) (Gambar 10).

Sebaran bobot $(\mathrm{kg})$ yellowfin yang berhasil diukur (55 ekor) berkisar 2,1-2,5 kg (27,3\%), bigeye (25 ekor) berkisar $2,1-2,5 \mathrm{~kg}(56,0 \%)$, cakalang (85 ekor) berkisar 1,6-2,0 kg (37,6\%), dan tongkol (39 ekor) berkisar 0,6-1,0 kg (92,3\%) (Gambar 11).

Hubungan panjang bobot ikan dominan hasil tangkapan yang dilakukan dengan menggunakan rumus Bal \& Rao (1984) menunjukkan bahwa pertumbuhan ikan yellowfin, bigeye, cakalang, dan tongkol bersifat alometrik negatif (pertambahan panjang lebih cepat dari bobot) (Gambar 12). 
Perikanan Tuna Skala Rakyat (Small Scale) di Prigi, Trenggalek-Jawa Timur (Nurdin, E.)
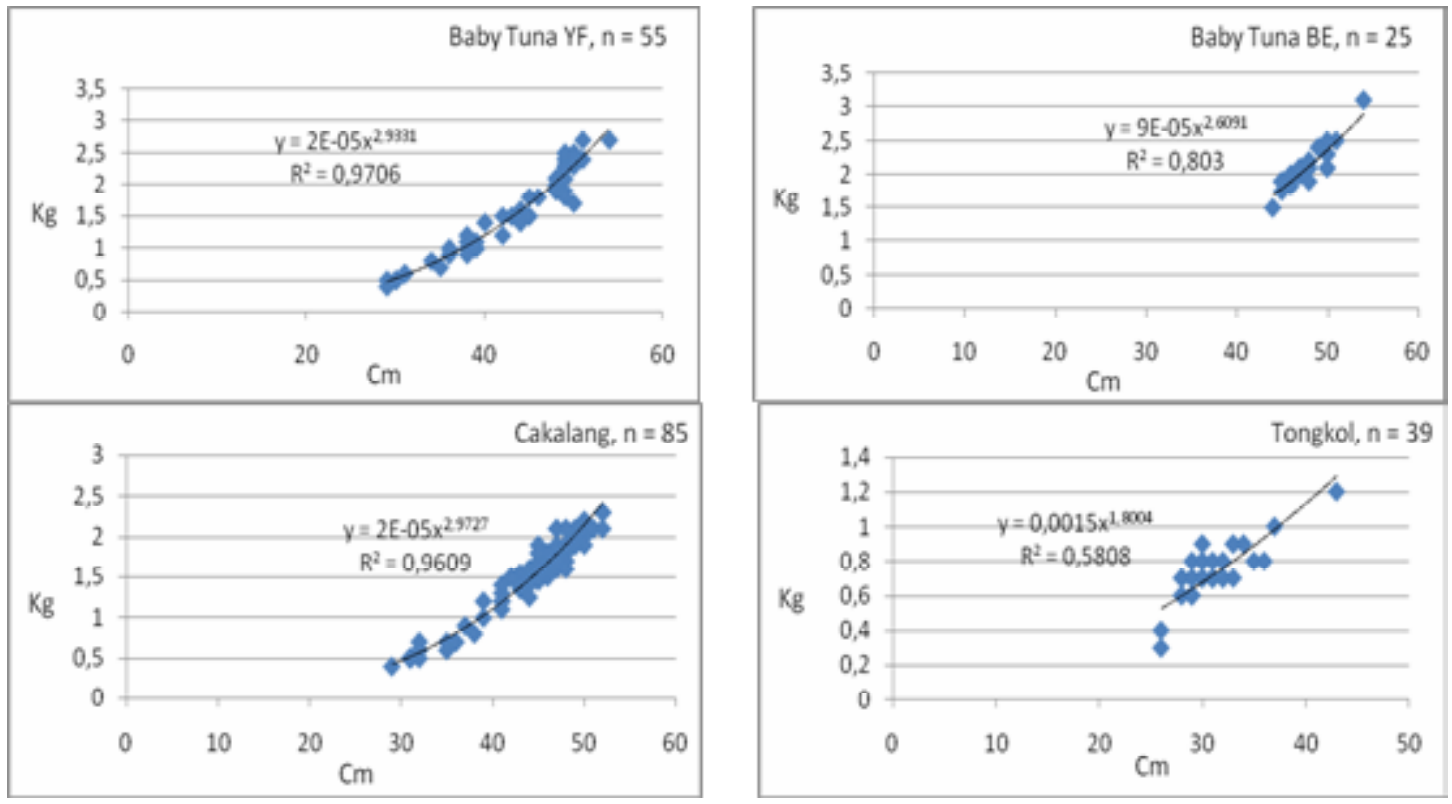

Gambar 12. Hubungan panjang bobot ikan hasil tangkapan nelayan Prigi.

\section{KESIMPULAN}

1. Adanya trendmenurun secara global terhadap nilai catch per unit of effort.

2. Musim ikan di Pelabuhan Perikanan Nusantara Prigi terjadi pada bulan Agustus-Desember dengan puncak musim pada bulan Oktober.

3. Hasil pengukuran biologi menunjukkan ikan tuna hasil tangkapan nelayan Prigi relatif berukuran kecil.

4. Hubungan panjang bobot alometrik negatif, (pertambahan panjang lebih cepat dari bobot).

\section{PERSANTUNAN}

Kegiatan dari hasil riset monitoring tuna di perairan Samudera Hindia, T. A. 2008, di Balai Riset Perikanan Laut, Muara Baru-Jakarta.

\section{DAFTAR PUSTAKA}

Bal, D. V. \& K. V. Rao. 1984. Marine Fisheries. Tata Mc. Graw-Hill Publishing Company Limited. New Delhi.

Collette, B. B. \& C. E. Nauen. 1983. FAO Species Catalogue, Vol. 2. Scombridae of the World, an Annotated and Illustrated Catalogue of Tunas, Mackerels, Bonitos, and Related Species Known to Date. United Nation Development Programme, Food, and Agriculture Organization of the United Nations, Rome. 137 pp.

Mertha, I. G. S., M. Nurhuda, \& A. Nasrullah. 2006. Perkembangan perikanan tuna di Pelabuhan Ratu. Jurnal Penelitian Perikanan Indonesia. 12 (2): 117-127. 